\title{
23. MAGNETIC FABRICS AND SOURCES OF MAGNETIC SUSCEPTIBILITY IN LOWER CRUSTAL AND UPPER MANTLE ROCKS FROM HESS DEEP1
}

\author{
Carl Richter, ${ }^{2}$ Paul R. Kelso, ${ }^{3}$ and Christopher J. MacLeod ${ }^{4}$
}

\begin{abstract}
We present a magnetic fabric study of mafic and ultramafic rocks recovered at Ocean Drilling Program Sites 894 and 895 from Hess Deep, a tectonic rift in the equatorial East Pacific $\left(2^{\circ} 15^{\prime} \mathrm{N}, 101^{\circ} 30^{\prime} \mathrm{W}\right)$. We demonstrate, using thermomagnetic curves and high-field (up to $1.5 \mathrm{~T}$ ) susceptibility measurements, that the magnetite contributes $>95 \%$ of magnetic susceptibility of these rocks. Bulk susceptibilities for the Site 894 gabbroic rocks are on average $1.72 \times 10^{-2}$ and for the Site 895 peridotites $4.29 \times 10^{-2}$ (SI volume units). The anisotropy of magnetic susceptibility is moderate to high and average $k_{\max } / k_{\min }$ is 1.15 ( $k_{\max }$ $\geq k_{\text {int }} \geq k_{\min }$ are the principal susceptibilities) at Site 894 and 1.11 at Site 895. Because of the pervasive serpentinization and the formation of randomly distributed secondary magnetite, the magnetic fabrics of the Site 895 peridotites show no apparent relationship to structural features. In the foliated gabbroic rocks from Site 894, we observe a close relationship between magmatic flow fabrics (defined by the preferred orientation of plagioclase) and magnetic fabrics: $k_{\min }$ is perpendicular to the macroscopic foliation and $k_{\max }$ dips steeply within the foliation plane and is parallel to the magmatic mineral lineation. Macroscopically isotropic gabbros yield the same principal susceptibility directions as the foliated gabbros. We interpret magnetic fabrics in these rocks to represent a weakly developed rock fabrics. We argue that the process for the development of the AMS is a distribution anisotropy which is caused by the growth of equant, irregular, or skeletal magnetite grains into a preferredly oriented (by magmatic flow) plagioclase "template." Magnetic fabric data record a mineral preferred orientation with a north-south, East Pacific Rise parallel strike and a near-vertical inclination, and can be interpreted to record the upward flow of melt at the top of an axial magma chamber into the base of an overlying sheeted dike complex.
\end{abstract}

\section{INTRODUCTION}

Sites 894 and 895 of Ocean Drilling Program (ODP) Leg 147 are located in Hess Deep on the eastern flank of the East Pacific Rise (EPR) in the equatorial East Pacific (Fig. 1). The unique position at the tip of a westward-propagating rift between the Cocos and Nazca Plates makes Hess Deep an ideal target to study magnetic properties in a vertical section of lower crustal and upper mantle rocks at a fast spreading $(130 \mathrm{~mm} / \mathrm{yr}$ ) oceanic ridge. The western end of the rift valley is situated in approximately 1-Ma-old EPR crust. The drill sites are located on an intrarift ridge in water depths of about $3023 \mathrm{~m}$ (Site 894 ) and about $3820 \mathrm{~m}$ (Site 895) in an area that has been geologically mapped by submersibles (Francheteau et al., 1990; Karson et al., 1992).

We discuss the rock magnetic properties of basically two different rock types (peridotites and gabbroic rocks, that are both affected by varying degrees of serpentinization and alteration). Hole $894 \mathrm{G}$ was drilled to 154 meters below seafloor (mbsf) and mainly gabbronorites and olivine gabbros were recovered; Hole $895 \mathrm{D}$ was drilled to 94 mbsf and mainly harzburgites were recovered. Hole $895 \mathrm{E}$ reached 88 mbsf and was drilled mainly through dunites, gabbroic rocks, and harzburgites (Gillis, Mével, Allan, et al., 1993).

'Mével, C., Gillis, K.M., Allan, J.F., and Meyer, P.S. (Eds.), 1996. Proc. ODP, Sci. Results, 147: College Station, TX (Ocean Drilling Program).

2Ocean Drilling Program and Department of Geology and Geophysics, Texas A\&M University, 1000 Discovery Drive, College Station, TX 77840, U.S.A

${ }^{3}$ Institute for Rock Magnetism, University of Minnesota, Minneapolis, MN 55455. (Current address: Lake Superior State University, Sault Sainte Marie, MI 49783. U.S.A.)

${ }^{4}$ Department of Earth Sciences, University of Wales College of Cardiff, P.O. Box 914, Cardiff CF1 3YE, United Kingdom. Formerly at: Institute of Oceanographic Sciences, Brook Road, Wormley, Surrey GU8 5UB, United Kingdom; and Borehole Research, Department of Geology, University of Leicester, Leicester LEI 7RH, United Kingdom. macleod@ cardiff.ac.uk

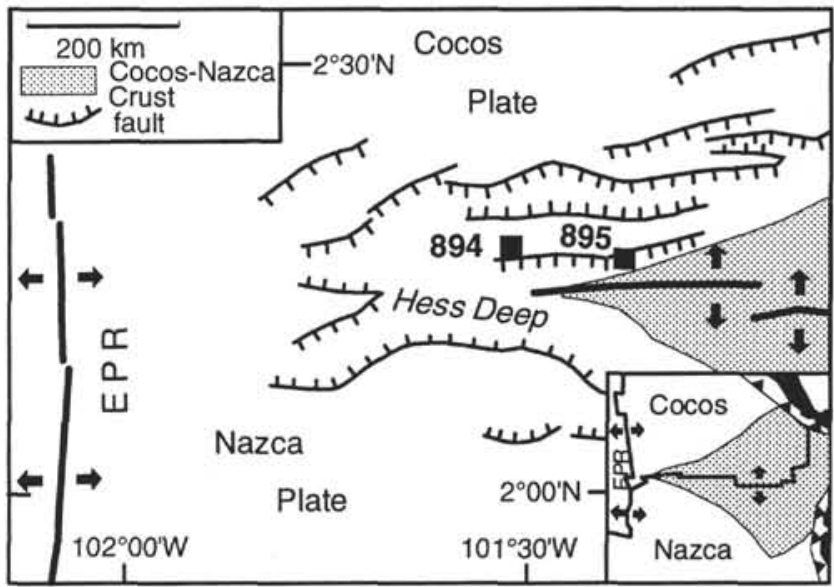

Figure 1. Location of Leg 147 Sites 894 and 895 and generalized tectonic setting of the Hess Deep rift in the equatorial East Pacific (after Lonsdale, 1988) near the junction of the East Pacific Rise (EPR) and the Galapagos spreading center (inset).

The anisotropy of magnetic susceptibility (AMS; reviews by Borradaile, 1988; Tarling and Hrouda, 1993) of most rock-forming minerals (e.g., paramagnetic muscovite, biotite, chlorite) is linked to the crystallographic lattice, that is, the principal susceptibility axes depend on the crystal symmetry (Nye, 1985), parallel to the crystallographic axes (magnetocrystalline anisotropy; e.g., Borradaile and Werner, 1994). This relationship allows the use of magnetic anisotropies as an easy-to-apply proxy for measuring crystallographic preferred orientations (Hrouda and Schulman, 1990; Richter et al., 1993) if it can be demonstrated that the magnetic fabric is due to minerals 
with a magnetocrystalline anisotropy (e.g., Housen and van der Pluijm, 1990). The magnetic anisotropy of ferrimagnetic magnetite is caused by shape anisotropy (Uyeda et al., 1963); that is, for multidomain magnetite, the maximum susceptibility is parallel to the long mineral axis and the minimum susceptibility parallel to the short axis. The magnetic susceptibility of magnetite is many times higher than the susceptibility of paramagnetic minerals and small traces of magnetite can entirely dominate the magnetic susceptibility. Alignment or preferred distribution of (equant) magnetite grains can lead to a distribution anisotropy (Wolff et al., 1989; Hargraves et al., 1991; Stephenson, 1994). AMS data can only be interpreted meaningful if the sources of magnetic susceptibility are known.

The anisotropy of remanence, especially the anisotropy of anhysteretic remanent magnetization (AARM; McCabe et al., 1985; Jackson, 1991), measures the anisotropy of ferro(i)magnetic minerals only. In this technique, an anhysteretic remanent magnetization (ARM) is imparted to a sample using a low steady (bias) magnetic field superimposed on the alternating field of an alternating field (AF) demagnetizer. The resulting ARM is measured and the process is repeated in nine different orientations. If both the $\mathrm{AF}$ and the direct current (DC) field are well below the coercivities of hematite, goethite, and fine-grained pyrrhotite, the AARM can only be due to the magnetic anisotropy of magnetite, coarse-grained pyrrhotite, or greigite.

The few studies on the magnetic anisotropy of ultramafic rocks from the oceanic crust (Smith and Banerjee, 1985; MacDonald and Ellwood, 1988; Bina et al., 1990; Bina and Henry, 1990) have shown the existence of relatively strong magnetic anisotropies. Serpentinized peridotites from Hole 670A in the Mid-Atlantic Ridge south of the Kane Fracture Zone show that $k_{\min }$ clusters around [010] of olivine (i.e., parallel to the spinel foliation) and $k_{\max }$ around the spinel lineation (Bina et al., 1990). This relationship appears to be invalid for highly serpentinized samples. Magnetic fabrics of samples from the Kane Fracture Zone are often related to the high-temperature deformation developed prior to serpentinization: the maximum axes that correspond to the long axes of magnetite particles are parallel to the tectonic lineation, and the minimum axes (perpendicular to the flattening of magnetite particles) are perpendicular to the foliation. Extensively serpentinized samples contain more dispersed secondary pseudo-single-domain magnetite and show little or no relationship between olivine crystallographic preferred orientation (CPO) and magnetic fabric. Wagner et al. (1981) studied the magnetic anisotropy of ophiolitic gabbros from the western Alps. The observed susceptibilities are low $\left(200-578 \times 10^{-6}\right)$ and the magnetic fabric is dominated by paramagnetic hornblende and augite minerals. In this case, AMS determines the CPO of the paramagnetic minerals, where $k_{\min }$ is parallel to the pole of the foliation plane and $k_{\max }$ parallel to the tectonic lineation. Ernst and Baragar (1992) inferred the magma flow pattern and magmatic processes of a huge dike swarm from AMS measurements on mafic igneous rocks which are macroscopically isotropic.

AMS is a very sensitive petrofabric tool, especially in rocks that lack a macroscopic fabric, as is the case in many of the isotropiclooking gabbros recovered at Hess Deep. Using 138 specimens obtained during Leg 147, our goal was to (1) quantify the sources of magnetic susceptibility and the origin of magnetic anisotropy in these mafic and ultramafic rocks, (2) investigate the orientation and shape of induced and remanent magnetic anisotropies, (3) use magnetic anisotropies to characterize the rock fabric, and (4) relate magnetic anisotropies to observed structural features.

\section{EXPERIMENTAL PROCEDURES}

Cylindrical specimens $($ diameter $=2.5 \mathrm{~cm}$, length $=2.2 \mathrm{~cm}$ ) were drilled from the working half of sampled cores. The anisotropy of low-field magnetic susceptibility (AMS) of the specimens was measured using a KLY-2 Kappabridge (Geofyzika Brno, inducing field $=$ $0.5 \mathrm{mT}$ ) on the JOIDES Resolution and with a custom-built susceptibility bridge (inducing field $=0.1$ and $1.0 \mathrm{mT}$ ) at the Institute for Rock Magnetism (IRM) at the University of Minnesota. The CS-2 furnace attachment for the Kappabridge at the IRM was used to determine the temperature dependence of magnetic susceptibility between room temperature and $700^{\circ} \mathrm{C}$. For AARM analysis, specimens were first demagnetized using a Schonstedt GSD-1 alternating field (AF) demagnetizer to obtain a baseline measurement that accounts for the remanent magnetizations that the AF demagnetizer did not remove. A DC-powered coil around the AF demagnetizer coil generates a steady magnetic field of $0.05 \mathrm{mT}$. The ARM was generated over the $0-95 \mathrm{mT}$ field range in nine different orientations. The sample was demagnetized after each step. The AARM tensor was calculated following the method of Girdler (1961). High-field susceptibilities (up to $1.5 \mathrm{~T}$ ) were determined using the Princeton Applied Research vibrating sample magnetometer (VSM) at the IRM. Magnetic anisotropy measurements are presented in Table 1.

\section{MAGNETIC SUSCEPTIBILITY}

The magnetic susceptibility $\left(k_{i j}\right)$ is the dimensionless proportionality factor between the magnitude of induced magnetic intensity $\left(M_{i}\right)$ and the applied magnetic field strength $\left(H_{j}\right)$ :

$$
M_{i}=k_{i j} H_{j}(\text { Nye, 1985), }
$$

where $k_{i j}$ is a second-rank symmetric tensor that can be visualized by an ellipsoid. The principal axes of the magnetic susceptibility ellipsoid are $k_{\max } \geq k_{\text {int }} \geq k_{\min }$ (e.g., Hrouda, 1982). Bulk susceptibility is defined as

$$
k=\left(k_{\max }+k_{\text {int }}+k_{\min }\right) / 3(\text { Nagata, 1961). }
$$

The ratio

$$
P=k_{\max } / k_{\min }(\text { Nagata, 1961) }
$$

is used to quantify the degree of anisotropy. SI volume units are used throughout.

The ellipsoids are represented in two types of diagrams that plot the principal values (directions and magnitudes): (1) lower hemisphere equal area stereograms of the principal directions using the conventions proposed by Ellwood et al. (1988) and (2) Flinn-type diagrams (Flinn, 1962) of the ellipsoid shape in the two-dimensional space.

\section{SOURCES OF MAGNETIC SUSCEPTIBILITY}

We applied two methods to investigate the sources of magnetic susceptibility: (1) the comparison between high-field $\left(k_{H F}\right)$ and lowfield $\left(k_{L F}\right)$ susceptibility (Rochette and Fillion, 1988; Hrouda and Jelinek, 1990), and (2) thermomagnetic behavior (e.g., Bina and Henry, 1990; Schmidt, 1993) using $k$ vs. temperature $k(T)$ curves. A discussion and comparison of both methods is given in Richter and van der Pluijm (1994). In high magnetic fields (1-1.5 T), above the saturation magnetization of the ferrimagnetic minerals, only diamagnetic $\left(k_{D}\right)$, paramagnetic $\left(k_{P}\right)$, and antiferromagnetic $\left(k_{A F}\right)$ susceptibilities are measured: $k_{H F}=k_{D}+k_{P}+k_{A F}$. In low fields $(0.1-0.5 \mathrm{mT})$ the ferrimagnetic minerals $\left(k_{F}\right)$ also contribute to the magnetic susceptibility, so that $k_{L F}=k_{F}+k_{D}+k_{P}+k_{A F}$. It follows from these equations that 
the ferrimagnetic contribution to magnetic susceptibility is calculated by

$$
k_{F}=k_{L F}-k_{H F} .
$$

Acquisition curves of the isothermal remanent magnetization (IRM) of samples from both sites show that magnetic saturation occurs well below $200 \mathrm{mT}$ (Fig. 2), which is indicative of magnetite or maghemite. The differences in the saturation magnetization are due to the magnetite concentration. At both sites, pseudo-single-domain magnetite is the magnetic carrier mineral (for a detailed characterization of the magnetic mineralogy, see Kelso et al., Pariso et al., both this volume). At both sites, $k_{H F}$ is between one and two orders of magnitude lower than $k_{L F}$ (Fig. 3A, B) which demonstrates that $k_{F}$ dominates the low-field magnetic susceptibility. Figure $3 \mathrm{C}$ shows $100\left[\left(k_{L F}\right.\right.$ $\left.\left.-k_{H F}\right) / k_{L F}\right] \%$ for Site 894 and Site 895 samples plotted vs. bulk susceptibility. The graph shows that the ferrimagnetic dominance increases with increasing bulk susceptibility which implies that the bulk susceptibility is a function of the magnetite concentration. The histogram of the bulk susceptibilities (Fig. 3C), in comparison with the percent ferrimagnetic contribution, demonstrates that the susceptibility of all samples is strongly magnetite-dominated.

Figure 4 shows two $k(T)$ curves $\left(25^{\circ}-700^{\circ} \mathrm{C}\right)$ for two samples from Sites 894 and 895 . The arrow indicates the heating and the cooling parts of the curve. Both curves are essentially reversible, indicating little chemical change during the heating process. Sharp Curie temperatures $\left(T_{C}\right)$ at $562^{\circ} \mathrm{C}$ (Sample 147-894G-20R-3, $124 \mathrm{~cm}$ ) and
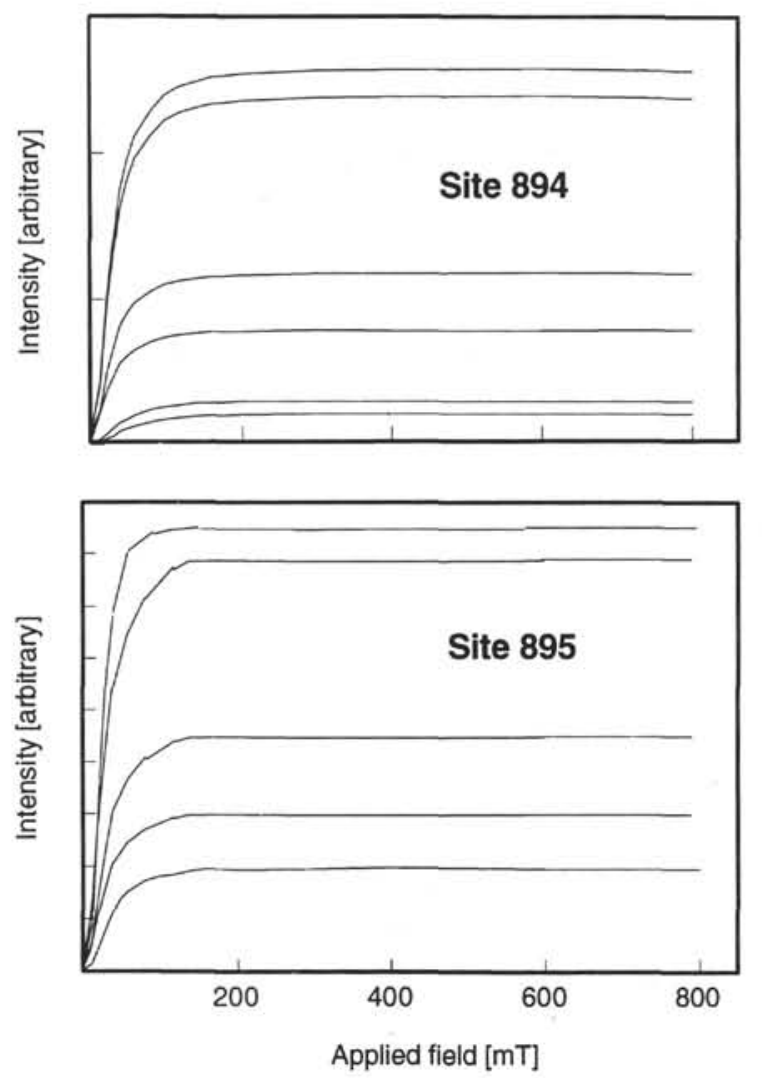

Figure 2. Acquisition curves of the isothermal remanent magnetization. Magnetic saturation for all samples occurs well below $200 \mathrm{mT}$, indicating magnetite or maghemite. $575^{\circ} \mathrm{C}$ (Sample $147-895 \mathrm{E}-1 \mathrm{R}-2,125 \mathrm{~cm}$ ) indicate the presence of magnetite with low $\mathrm{Ti}$ content and almost pure magnetite ( $T_{C}$ of pure magnetite $=580^{\circ} \mathrm{C}$ ) (see Kelso et al., Pariso et al., both this volume). Below $T_{C}$, the magnetic susceptibility stays constant or increases slightly with increasing temperature. This behavior is typical for the thermomagnetic behavior of magnetite (e.g., Schmidt, 1993) without a paramagnetic contribution. A very shallow Hopkinson peak can be observed in both samples. A susceptibility decrease with increasing temperature following the Curie-Weiss law would indicate an influence of paramagnetic material to the bulk susceptibility (SchultzKrutisch and Heller, 1985; Richter and van der Pluijm, 1994).

Both methods demonstrate that the dominant source of magnetic susceptibility and, hence, of magnetic susceptibility anisotropy is magnetite for both the Site 894 gabbros and gabbronorites and the Site 895 peridotites. Magnetic fabrics, therefore, represent the overall shape and distribution of magnetite in these rocks. Olivine, pyroxene, amphiboles, serpentine, ilmenite, pyrrhotite, and the diamagnetic plagioclase also contribute to some degree, but have only very minor influence on the magnetic susceptibility tensor.

\section{BULK SUSCEPTIBILITY}

Figure 5 shows the observed magnetic bulk susceptibilities separately for the three principal holes. The values are high and range from $2.78 \times 10^{-4}$ to $1.35 \times 10^{-1}$. The mean value for the Site 894 rocks is $1.72 \times 10^{-2}$ and for the Site 895 peridotites, $4.29 \times 10^{-2}$, which is similar to previously reported values from oceanic mafic and ultramafic rocks (Fox and Opdyke, 1973; Kent et al., 1978). Susceptibility values between $4.27 \times 10^{-4}$ and $4.32 \times 10^{-1}$ have been determined from the ODP Hole 735B gabbros (Kikawa and Pariso, 1991).

The vertical distribution of magnetic susceptibilities in Holes $894 \mathrm{G}, 895 \mathrm{D}$, and $895 \mathrm{E}$ is shown in Figure 5. Magnetite is the major source of magnetic susceptibility and, hence, variations in the magnetic susceptibility directly reflect variations in the concentration of magnetite (Kelso et al., this volume). Hole $894 \mathrm{G}$ shows no systematic distribution of magnetic susceptibilities with depth. A correlation between lithology (see simplified lithostratigraphic column in Fig. 5) and $k$ does not exist. Hole 895D shows a trend towards higher susceptibilities downhole, which indicates an increase in the concentration of magnetite. Again, no relationship between $k$ and lithology is evident. Samples from Hole 895E reach the highest observed susceptibilities and display a large scatter in bulk susceptibilities.

\section{MAGNETIC FABRICS}

\section{Anisotropy of Magnetic Susceptibility}

Ferrimagnetic minerals have a shape anisotropy that is caused by the demagnetizing field, $H_{\text {demag }}$, which reduces the external field $H_{e x t}$ depending on the shape and orientation of the magnetized body. The effective field $H_{e f f}$ is

$$
H_{e f f}=(1 / k-N) M
$$

where $N$ is the demagnetizing factor (e.g., Osborn, 1945). Pfleiderer and Halls (1990) investigated the relationship between shape and AMS of artificial samples and found that AMS is related inversely to the demagnetization factor, which itself relates inversely to the axial ratios of the ferrimagnetic grains. AMS provides a direct measure of the overall magnetite shape. A second mechanism to obtain a significant ferrimagnetic anisotropy is the distribution of the grains. For example, an alignment of spherical magnetite grains in a plane will lead to a higher susceptibility parallel to that plane than perpendicular to it. This phenomenon has been described as distribution anisotropy (Hargraves et al., 1991). 

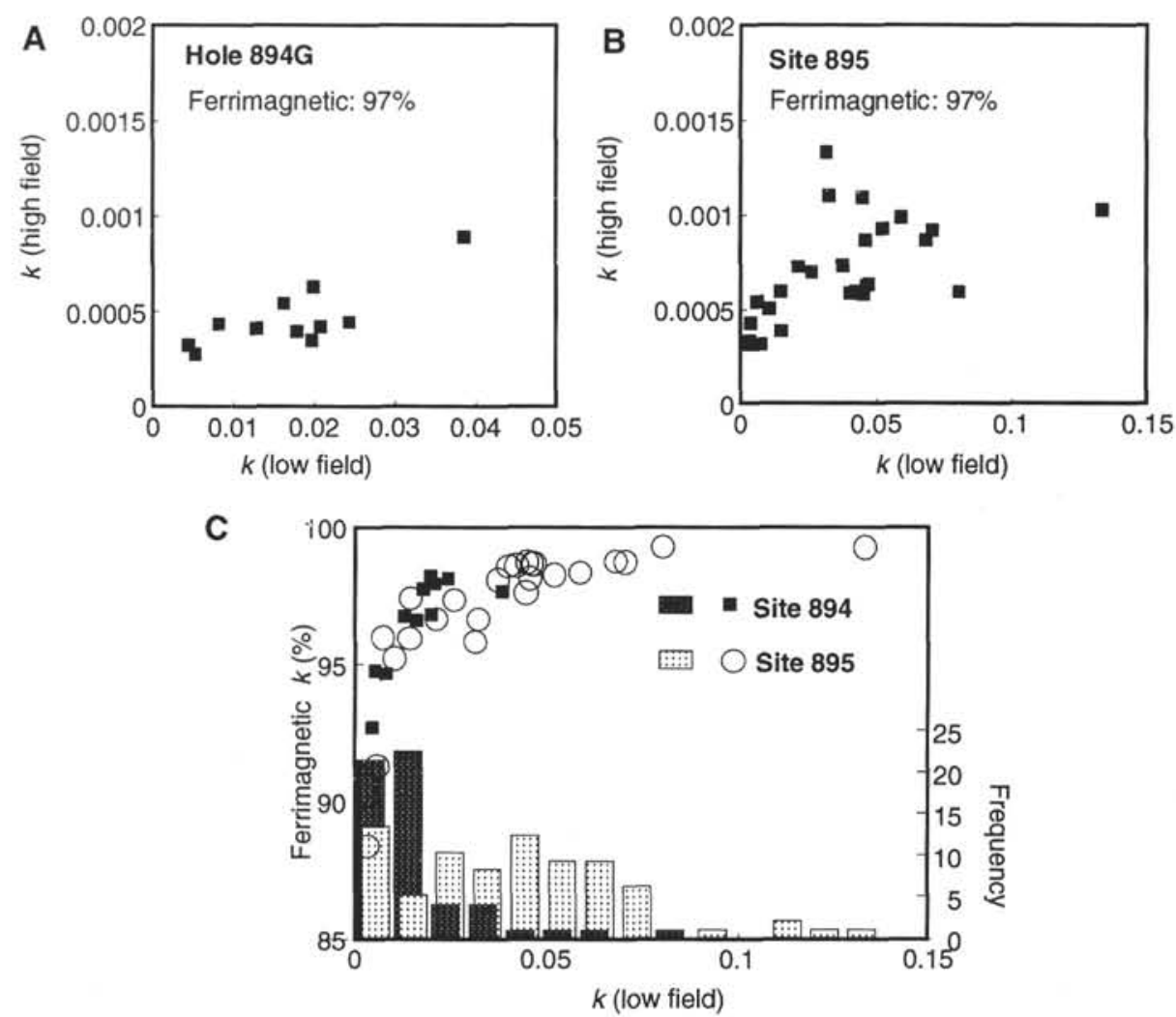

Figure 3. A, B. High-field susceptibility plotted vs. low-field susceptibility. The low-field susceptibility is 1-2 orders of magnitude higher, indicating a strong magnetite dominance. The contribution of ferrimagnetic magnetite to the low-field susceptibility is on average $97 \%$ at both sites. C. Ferrimagnetic contribution (in percent) to low-field susceptibility of individual samples plotted vs. bulk susceptibility and histogram of bulk susceptibilities. Most samples have a susceptibility that is dominated by magnetite to at least $95 \%$.

AMS results are presented in Table 1. The magnetic anisotropy is moderate to high in most samples. Figure 6 shows the degree of anisotropy $P$ plotted vs. depth and lithology. Anisotropies are highest in Hole $894 \mathrm{G}$ gabbros and there is a tendency of increasing anisotropy downhole to about $100 \mathrm{mbsf}$, where the highest anisotropies are reached. $P$ varies between 1.01 and 1.42 (average $=1.15$ ) at Hole $894 \mathrm{G}$, between 1.03 and 1.18 (average $=1.10$ ) at Hole 895D, and between 1.03 and 1.25 (average $=1.12$ ) at Hole 895E. The lithology has no apparent influence on the anisotropy or on the ellipsoid shape. AMS ellipsoid shapes are presented in Flinn diagrams (Flinn, 1962) in Figure 7. The shapes of the susceptibility ellipsoids scatter between oblate, prolate, and almost isotropic. Most are triaxial, that is, they cluster around the dashed line of the Flinn diagrams $\left(k_{\max } / k_{\text {int }}=\right.$ $k_{\text {in }} / k_{\text {min }}$ ), except that samples from Hole $895 \mathrm{E}$ tend toward more oblate-shaped AMS ellipsoid forms.

The rotary-drilled cores have only a vertical (no horizontal) orientation and the principal susceptibility directions appear to be random for that reason (Table 1). In addition, the complicated tectonic situation within the rift (e.g., Karson et al., 1992) adds another factor that apparently randomizes the orientation of the susceptibility ellipsoids. Stable paleomagnetic directions have an average inclination of $38^{\circ}$ at Site 894 (Pariso et al., this volume) and no consistent inclination at Site 895 (Kelso et al., this volume), although the calculated dipole field inclination at the latitude of Hess Deep is $+4.6^{\circ}$. This implies that major block rotations occurred, and not only the horizontal orientation but also the vertical orientation before tectonic rotation and drilling is uncertain. The dip of the principal susceptibility axes, however, should be unaffected by the lack of azimuthal control and should yield an estimate of the mean inclination of the susceptibility axes after the rift-related tectonic rotation. Figure 8 shows histograms of the dip of $k_{\min }$ for the three principal holes. At Hole $894 \mathrm{G}$ it is apparent that the pattern is not random and that most $k_{\min }$ axes have a shallow dip with an average of $25^{\circ}$. The $k_{\min }$ distribution at Hole $895 \mathrm{D}$ is very scattered and shows no significant maximum. The scatter is also considerable at Hole $895 \mathrm{E}$ but a distinct maximum is reached at $30^{\circ}$. The dip of $k_{\min }$ is generally shallow and shows a very systematic distribution at Holes $894 \mathrm{G}$ and $895 \mathrm{E}$. This suggests that the orientation of the AMS ellipsoids in a geographical reference frame bear a geological significance.

\section{Anisotropy of Anhysteretic Remanent Magnetization}

ARM anisotropy measures a remanent magnetization and, hence, determines the fabric of the carriers of remanence, that is, magnetite only (Kelso et al., Pariso et al., both this volume). We have demonstrated that AMS is also dominated by magnetite. Both methods should yield a comparable result if the measured effective magnetic grain size is the same. Figure 9 compares the AMS and the AARM ellipsoids of three samples from the three main holes. Figure 9A shows the magnetic fabrics of a gabbronorite from Hole $894 \mathrm{G}$. The shape of the prolate ellipsoids and the orientations of the principal directions are virtually the same, but $P_{A M S}$ is higher than $P_{A A R M}$. A harzburgite sample from Hole 895D (Fig. 9B) has triaxial ellipsoid shapes and the principal directions of the AMS and AARM ellipsoids are only a few degrees apart. The dunite sample from Hole 895E (Fig. $9 \mathrm{C})$ has a strongly oblate fabric. $P_{\text {AARM }}$ is 1.38 and very strong compared to $P_{A M S}=1.02$, which is typical of the methods (Jackson, 1991). The orientation of the minimum axes is virtually identical, whereas 
the maximum and intermediate directions are rotated, as can be expected for a strongly oblate ellipsoid, on a great circle perpendicular to $k_{\min }$. Reasons for the deviation between the two tensors are that (1) AMS, though it is dominated by magnetite, is also influenced by paramagnetic and diamagnetic susceptibilities, and (2) AARM and AMS do not measure the same effective magnetic grain size.

\section{DISCUSSION}

The orientation of the magnetic fabric of ultramafic rocks has been demonstrated to be related to structural features and flow patterns (Smith and Banerjee, 1985; MacDonald and Ellwood, 1988; Bina et al., 1990; Wagner et al., 1981). The macroscopic fabrics of the gabbroic rocks collected at Site 894 are either isotropic or foliated. The foliation is defined by the shape-preferred orientation of crystals, mainly plagioclase, and is related to magmatic flow (Gillis, Mével, Allan, et al., 1993). In contrast to samples from Hole 735B (ODP Leg 118), the rocks show little evidence for solid-state penetrative deformation. The orientation of the near-vertical foliation is generally north-south with a steeply plunging lineation (Fig. 10; MacLeod, Boudier, et al., this volume).

Figure 11 shows the principal susceptibility axes of foliated gabbros from Hole $894 \mathrm{G}$. The data are corrected for the stable magnetic remanence (Kelso et al., this volume; Pariso et al., this volume), that is, to a common declination $\left(0^{\circ}\right.$, normal polarity) and inclination $\left(+4.6^{\circ}\right.$, the calculated dipole field inclination for the latitude of Hess Deep). A comparison with the structural data from Figure 10 shows that $k_{\max }$ is parallel to the mineral lineation and that $k_{\min }$ is parallel to the poles of foliation. $k_{\max }$ has a steeply dipping orientation and scatters on a great circle within the foliation plane. $k_{i n t}$ and $k_{\min }$ are shallow-dipping. The magnetic fabric is directly related to the rock fabric, though the rock fabric is defined by the shape-preferred orientation of mainly plagioclase, which does not significantly contribute to AMS.

We have used this relationship to investigate the fabrics of macroscopically isotropic-looking gabbro samples from Hole 894G (Fig. 12). Compared to the fabric diagrams (Fig. 10) and the magnetic fab-
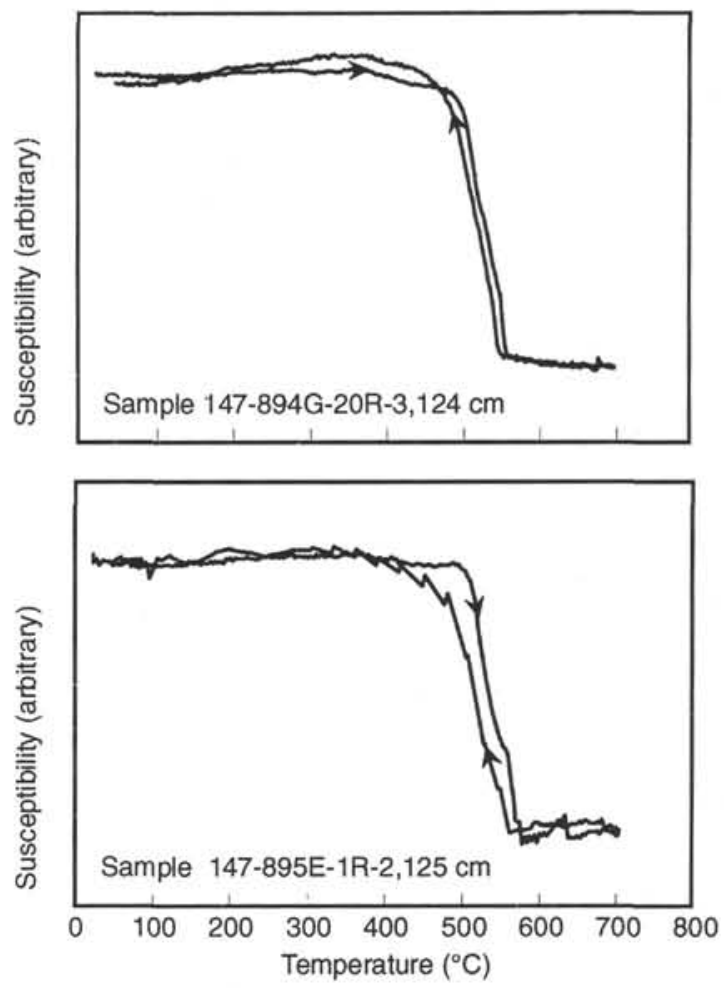

Figure 4. Heating and cooling curves of low-field susceptibility. Arrows indicate heating and cooling part of curve. No temperature dependence of the susceptibility before the intensity breakdown at the Curie temperature indicates that only ferrimagnetic magnetite contributes significantly to magnetic susceptibility. Both curves are virtually reversible, indicating little chemical change during heating. The Hopkinson peak is very shallow in both samples.

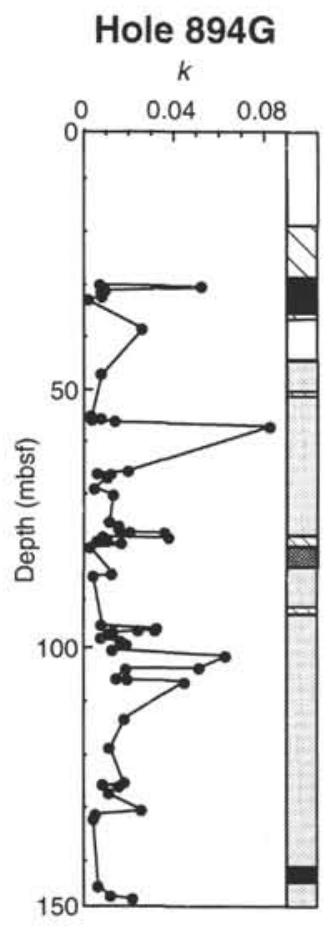

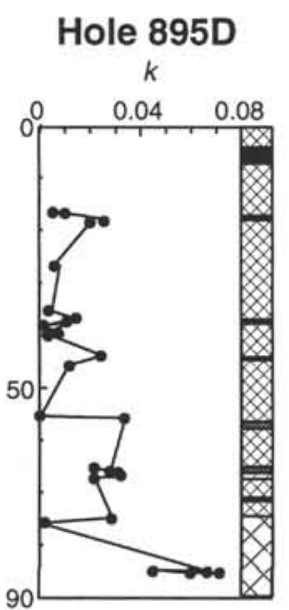

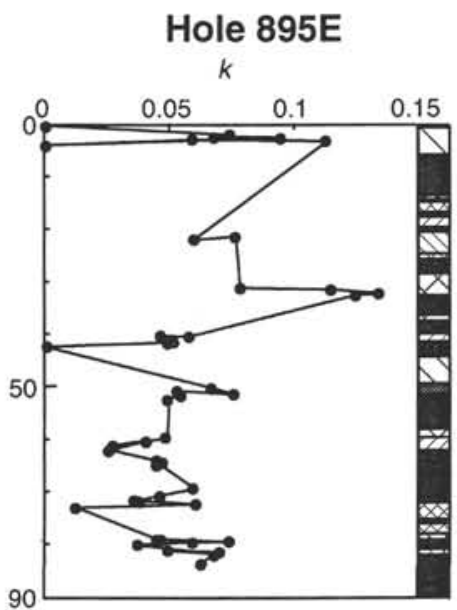

Lithology

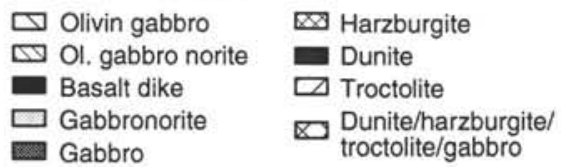

Figure 5. Bulk susceptibility plotted vs. depth and simplified lithology. The susceptibility magnitude is directly related to magnetite concentration. 
Table 1. Anisotropy of magnetic susceptibility.

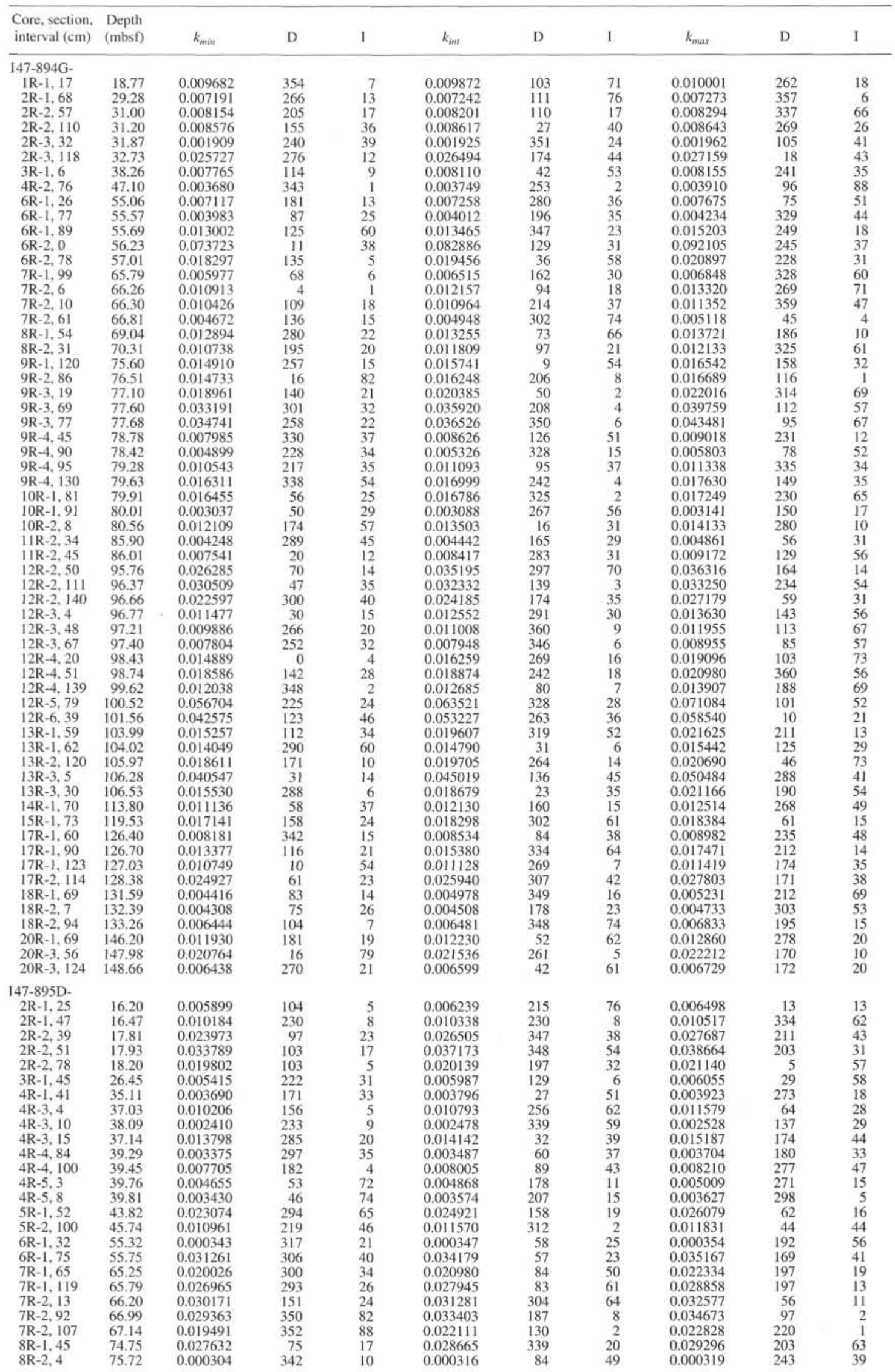


Table 1 (continued).

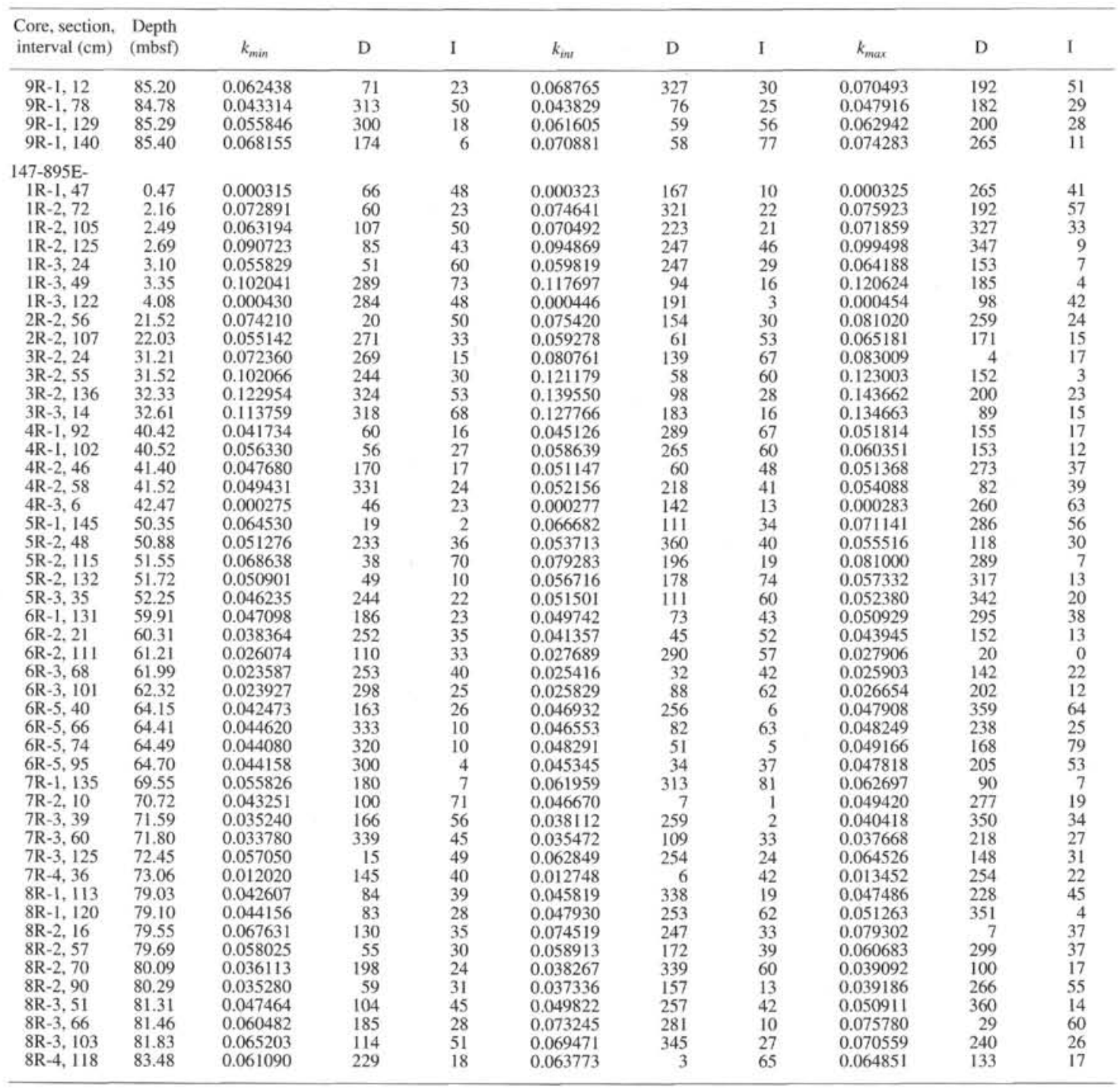

Notes: AMS measurements in SI units (volume susceptiblity). $\mathrm{D}=$ declination in degrees; $\mathrm{I}=$ inclination in degrees (core coordinates).

rics of the foliated gabbros (Fig. 11), the magnetic fabrics of the unfoliated samples show the same characteristics. $k_{\max }$ dips steeply to the northeast. The distribution of $k_{\text {min }}$ and $k_{\text {int }}$ is more scattered. Most $k_{\min }$ axes have an east to northeast direction and most $k_{\text {int }}$ axes dip shallowly to the south. Though a macroscopic fabric is not visible, we can infer from the magnetic fabric data that the isotropic gabbros have a steeply dipping magmatic lineation and north-south-oriented foliation. These structures are too weakly developed to be visible but can be detected with sensitive petrofabric indicators, like AMS.

We argue, that the process for the development of the AMS is a distribution anisotropy (Wolff et al., 1989; Hargraves et al., 1991; Stephenson, 1994). Magnetic grains do not have to be nonequant (elliptical, elongated, or flattened) and aligned in order to impart a detectable AMS. The effect may arise through organization of equant, irregular, or skeletal grains into planar or linear arrangements. It is not necessary that the grains actually grow during the magma flow period (and thus acquire a shape anisotropy), it is enough that the grains are arranged or grow along preexisiting fabric elements. Hargraves et al. (1991) argue that AMS in pristine igneous rocks is a direct or indirect reflection of preexisting silicate fabric, which is associated with flow or intrusion of the magma. They conclude that
AMS provides a direct record of fluid-dynamic histories of igneous rocks. The Hole $894 \mathrm{G}$ plutonic rocks contain primary igneous magnetite and ilmenite, which are now affected by exsolution and alteration. Thin sections show that the texture of the oxide minerals is predominantly interstitial, and equant in coarser and less deformed patches (Gillis, Mével, Allan, et al., 1993). The late-crystallizing interstitial minerals form thin cuspate-shaped grains between the silicates, partially or totally enclose silicates, or, where interstitial between plagioclase, make up subangular cross sections. The distribution of these grains will be relatively anisotropic if they grew in residual liquid volumes within a preferredly oriented (by magmatic flow) silicate (i.e., a plagioclase "template"). This mechanism explains (1) the origin of magnetic anisotropy in mafic and ultra mafic rocks from Hess Deep and (2) why macroscopic plagioclase fabrics and magnetite fabrics caused by interstitial and sometimes equant grains are parallel.

Magnetic fabric data demonstrate that the gabbros (Figs. 11 and 12) have a very uniform fabric with a steeply dipping magnetic/magmatic lineation and a near-vertical foliation (the plane perpendicular to $\left.k_{\min }\right)$. The average strike of the foliation is approximately northsouth, that is, parallel to the strike of the EPR spreading axis. Sheeted 
Figure 6. The degree of anisotropy $P=k_{\max } / k_{\min }$ plotted vs. depth and simplified lithology.

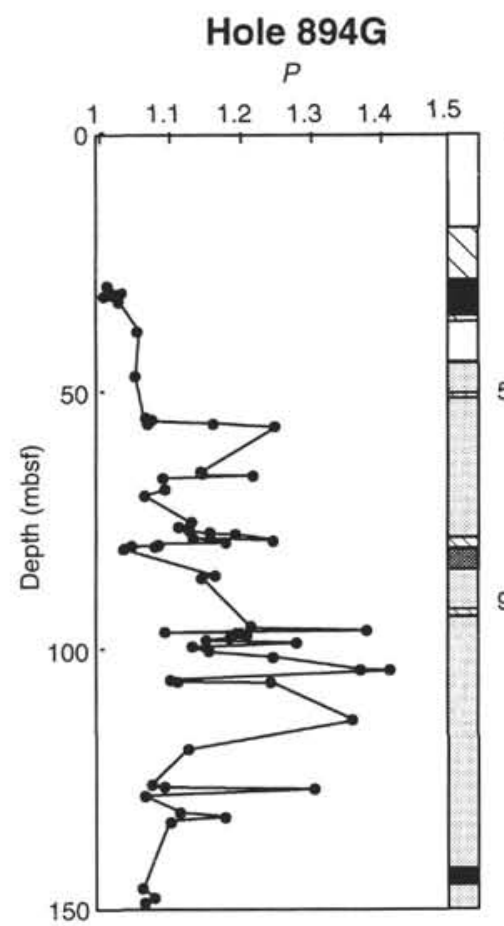

Hole 895D

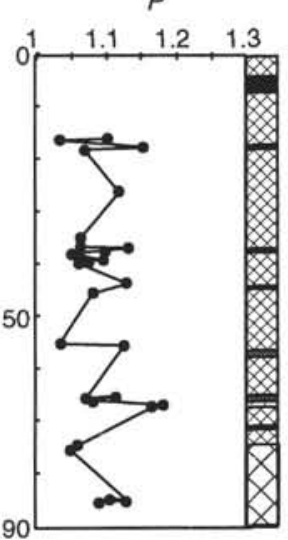

90
Hole 895E

$P$

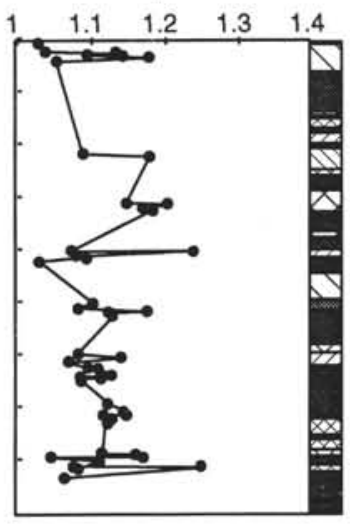

Lithology

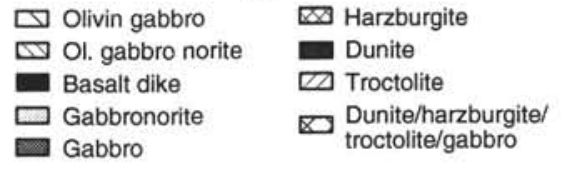

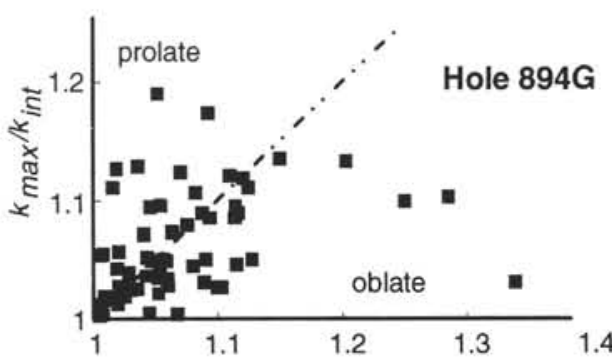
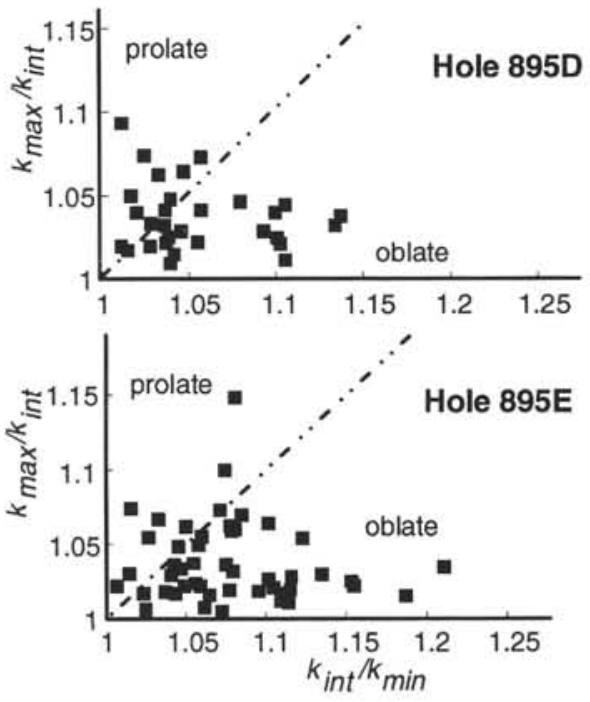

Figure 7. The shape of the magnetic susceptibility ellipsoid in Flinn diagrams. Most ellipsoids are triaxial; samples from Hole $895 \mathrm{E}$ have more oblate-shaped susceptibility ellipsoids.

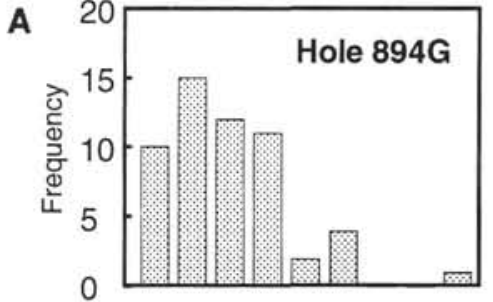

B
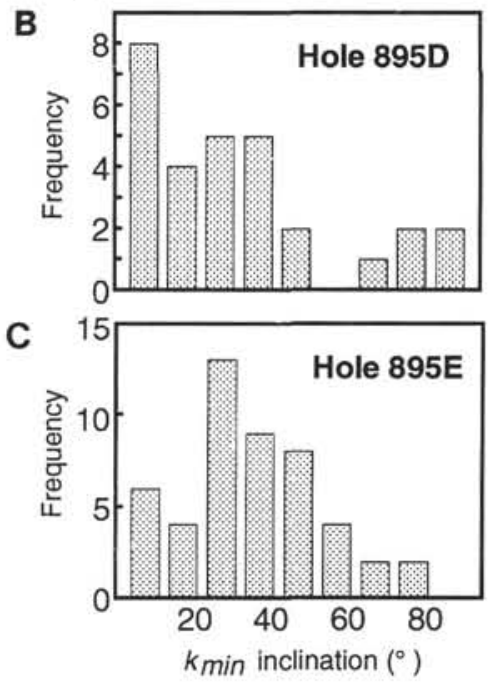

Figure 8. Histograms of the inclination of the minimum susceptibility axes of the three principal holes. A. The dip of $k_{\min }$ of the Hole $894 \mathrm{G}$ rocks is shallow, about $25^{\circ}$ on average. B. Hole $895 \mathrm{D}$ shows a large $k_{\min }$ scatter and no apparent maximum. C. Hole $895 \mathrm{E}$ samples show a large scatter, but have a distinct maximum at $30^{\circ}$. 

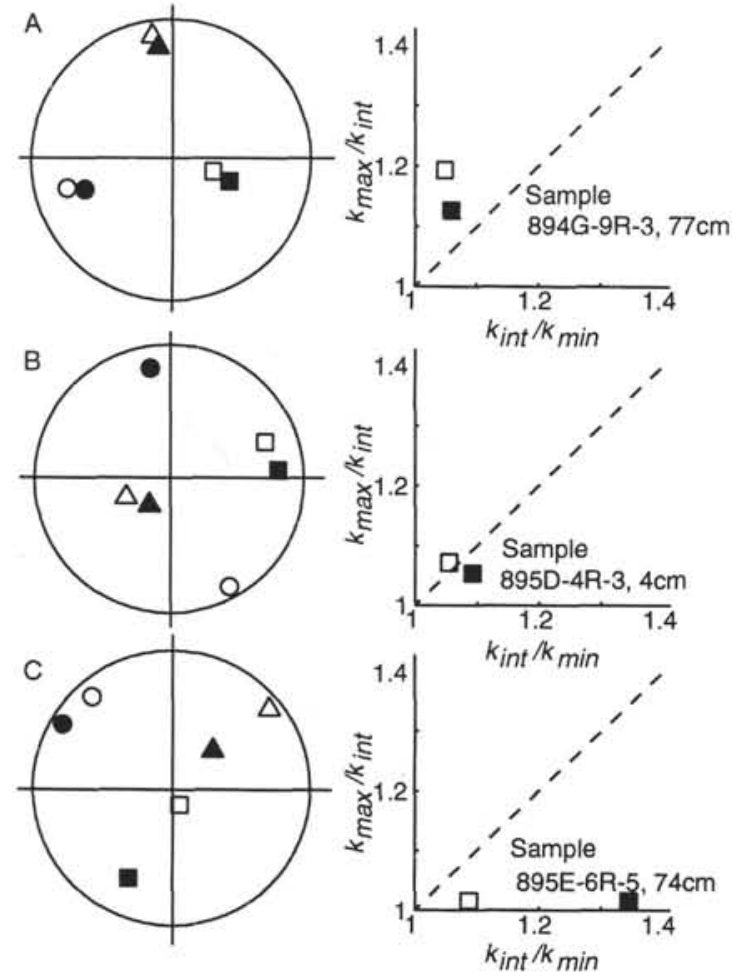

Figure 9. Comparison between AMS and AARM ellipsoids for selected samples. Square $=$ maximum; triangle $=$ intermediate circle $=$ minimum direction; open symbols $=$ AMS; solid symbols $=$ AARM. A, B. The principal directions and shapes of both ellipsoids compare well. C. The differences in orientation and degree of anisotropy demonstrate that for this sample both methods measure a different effective magnetic grain size.

dikes measured on the north wall of Hess Deep during Alvin dives (Karson et al., 1992) are near-vertical and also have an EPR-parallel north-south orientation. The steep lineations and foliations in the gabbros parallel to those in the sheeted dike complex have been interpreted to record the upward flow of melt at the top of the axial magma chamber into the base of a sheeted dike complex (Nicolas et al., 1988; MacLeod and Rothery, 1992).

Peridotites from Site 895 yielded no consistent stable paleomagnetic direction (Kelso et al., this volume). The dip of $k_{\min }$ in the unrotated data is very scattered, and a relationship between macroscopic features and AMS is not apparent. The randomly distributed secondary magnetite that was formed during the serpentinization process presumably randomizes the magnetic fabric and overprints any meaningful relationships between tectonic structures and magnetic fabrics.

\section{CONCLUSIONS}

Our magnetic fabric study of mafic and ultramafic rocks from Hess Deep demonstrates that AMS is a very sensitive method that can be used to identify and characterize rock fabrics even in rocks that appear to be macroscopically isotropic. In detail we demonstrated that:

1. High-field/low-field comparisons and thermomagnetic behavior show that magnetic susceptibilities (and, hence, magnetic fabrics) are dominated by magnetite.

2. Magnetic susceptibility anisotropy presumably originates from a distribution anisotropy which is caused by the growth of magnetite grains into a preexisiting silicate flow fabric. The degree of anisotro-
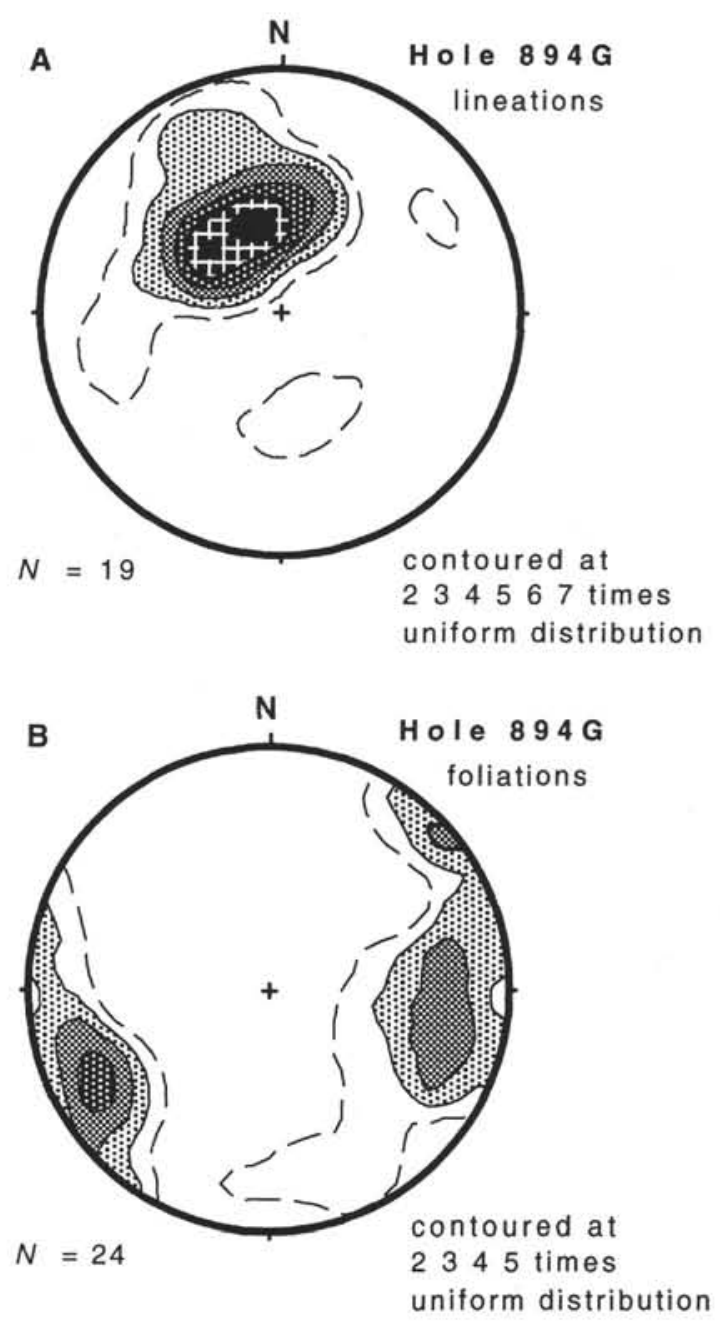

Figure 10. Structural features of foliated gabbros from Hole 894G (from MacLeod, Boudier, et al., this volume). A. Steeply dipping lineations. B. Magmatic foliations that are near-vertical and strike north-south, approximately parallel to the EPR axis.

py is moderate to high (average $k_{\max } / k_{\min }=1.15$ at Hole 894G, 1.10 at Hole $895 \mathrm{D}$, and 1.12 at Hole $895 \mathrm{E}$ ), susceptibility ellipsoids are in general triaxial. Lithology has no apparent influence on the shape of the anisotropy ellipsoid.

3. Anisotropies of remanence (AARM) and of susceptibility (AMS) both measure the overall preferred orientation or shape anisotropy of magnetite grains. The effective grain size determined by both methods is different, however, and orientation and shape of the anisotropy ellipsoids differ for that reason.

4. The mean dip of the minimum susceptibility axes after tectonic rotation due to rifting is $25^{\circ}$ for the Hole 894 gabbroic rocks.

5 . We did not observe a relationship between structural features and magnetic fabrics for the Site 895 peridotites. The formation of randomly oriented secondary magnetite during the serpentinization process obliterates any meaningful correlation between structural features and magnetic fabrics.

6. Rotation of the AMS directions of foliated gabbros from Site 894 into a common stable paleomagnetic direction (declination and inclination) shows that $k_{\min }$ is perpendicular to the observed magmatic foliation and $k_{\max }$ parallel to the magmatic lineation. The lineation is dipping steeply to the northeast and the foliation has a north-south 


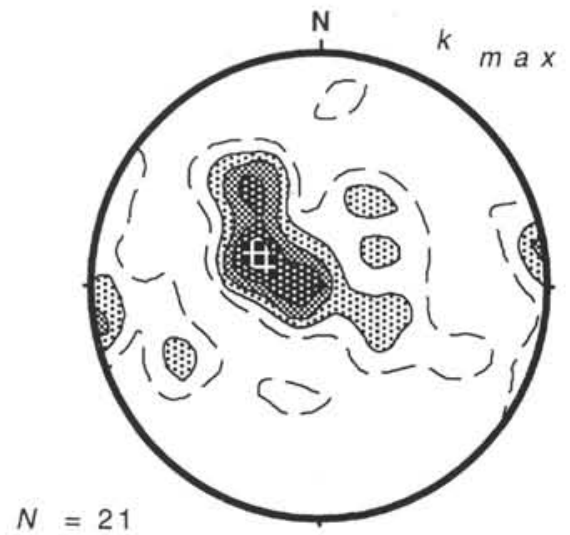

contoured at 23456 times uniform distribution
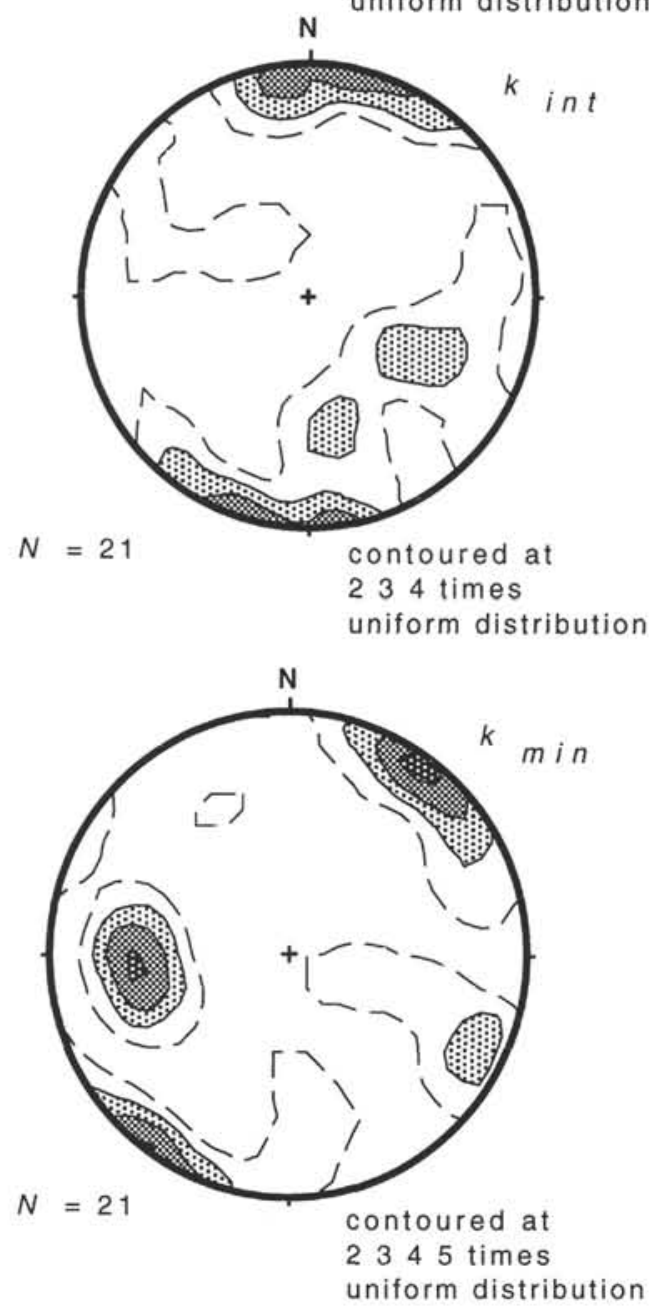

Figure 11. Principal magnetic susceptibility axes of macroscopically foliated gabbroic rocks from Hole $894 \mathrm{G}$. Values are restored to a common stable magnetic declination and inclination. $k_{\max }$ has a steep inclination that is parallel to the magmatic lineation and $k_{\min }$ a shallow inclination that is parallel to the poles to planes of the foliated gabbros (compare to Fig. 10).
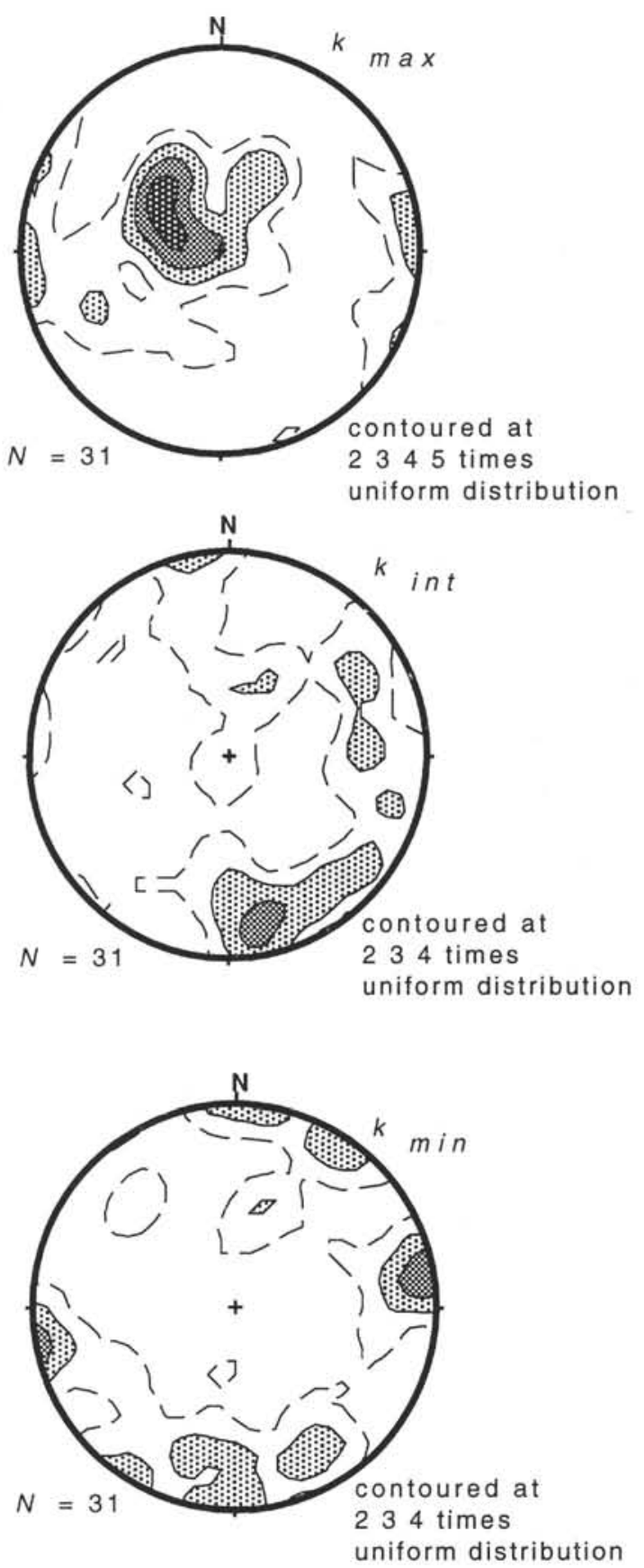

Figure 12. Principal magnetic susceptibility axes of macroscopically isotropic gabbroic rocks from Hole $894 \mathrm{G}$. Values are restored to a common stable magnetic declination and inclination. The orientation of the axes is the same as in the macroscopically foliated rocks and parallel to the lineation and foliation observed in the foliated gabbros.

strike that is parallel to the EPR. Rock fabrics are defined by the preferred orientation of plagioclase and magnetic fabrics determine the preferred orientation/distribution of magnetite.

7. Macroscopically isotropic gabbros have the same magnetic fabrics as the foliated gabbros. The minimum susceptibility axes are oriented about east-west and the maximum axes are near-vertical.

8. Structural and magnetic fabric data reveal a preferred orientation with an EPR parallel strike and a steep inclination. The rocks 
show little evidence for penetrative deformation and the structures are interpreted to represent magmatic flow fabrics. These fabrics are parallel to structures determined in the sheeted dikes from the north wall of Hess Deep (Karson et al., 1992) and can be interpreted to record the upward flow of melt at the top of the axial magma chamber into the base of a sheeted dike complex.

\section{ACKNOWLEDGMENTS}

Rock magnetic measurements were carried out at the Institute for Rock Magnetism (University of Minnesota). The IRM is funded by the Keck Foundation, the National Science Foundation, and the University of Minnesota. We thank Chris Hunt and Jim Marvin for their support. The thermomagnetic curves could not have been included without the help of Peat Solheid. We thank Peter Clift and reviewers Brooks Ellwood, Bernie Housen, Jamie Allan, and Shanna Collie for helpful comments on our manuscript. Shipboard scientists F. Boudier, B. Célérier, L. Kennedy, E. Kikawa, and J. Pariso contributed structural and paleomagnetic data. Research was supported by the Deutsche Forschungsgemeinschaft, grant RI576/1-2 (C.R.), USSSP grant 147-20719b (P.K.), and the Natural Environment Research Council (C.J.M.).

\section{REFERENCES}

Bina, M.M., and Henry, B., 1990. Magnetic properties, opaque mineralogy and magnetic anisotropies of serpentinized peridotites from ODP Hole 670A near the Mid-Atlantic Ridge. Phys. Earth Planet. Inter., 65:88103.

Bina, M.M., Henry, B., and Cannat, M., 1990. Magnetic anisotropy and some other magnetic properties of serpentinized peridotites from ODP Hole 670A. In Detrick, R., Honnorez, J., Bryan, W.B., Juteau, T., et al. Proc. ODP, Sci. Results, 106/109: College Station, TX (Ocean Drilling Program), 263-267.

Borradaile, G.J., 1988. Magnetic susceptibility, petrofabrics and strain. Tectonophysics, 156:1-20.

Borradaile, G.J., and Werner, T., 1994. Magnetic anisotropy of some phyllosilicates. Tectonophysics, 235:223-248.

Ellwood, B.B., Hrouda, F., and Wagner, J.-J., 1988. Symposia on magnetic fabrics: introductory comments. Phys. Earth Planet. Inter, 51:249-252.

Ernst, R.E., and Baragar, W.R.A., 1992. Evidence from magnetic fabric for the flow pattern of magma in the Mackenzie giant radiating dike swarm. Nature, 356:511-513.

Flinn, D., 1962. On folding during three-dimensional progressive deformation. Q. J. Geol. Soc. London, 118:385-433.

Fox, P.J., and Opdyke, N.D., 1973. Geology of the oceanic crust: magnetic properties of oceanic rocks. J. Geophys. Res., 78:5139-5154.

Francheteau, J., Armijo, R., Cheminée, J.L., Hekinian, R., Lonsdale, P., and Blum, N., 1990. 1 Ma East Pacific Rise oceanic crust and uppermost mantle exposed by rifting in Hess Deep (equatorial Pacific Ocean). Earth Planet. Sci. Lett., 101:281-295.

Gillis, K., Mével, C., Allan, J., et al., 1993. Proc. ODP, Init. Repts., 147: College Station, TX (Ocean Drilling Program).

Girdler, R.W., 1961. The measurement and computation of anisotropy of magnetic susceptibility of rocks. Geophys. J. R. Astron. Soc., 5:34-44.

Hargraves, R.B., Johnson, D., and Chan, C.Y., 1991. Distribution anisotropy: the cause of AMS in igneous rocks? Geophys. Res. Lett., 18:2193-2196.

Housen, B.A., and van der Pluijm, B.A., 1990. Chlorite control of correlations between strain and anisotropy of magnetic susceptibility. Phys. Earth Planet. Inter., 61:315-323.

Hrouda, F., 1982. Magnetic anisotropy of rocks and its application in geology and geophysics. Geophys. Surv., 5:37-82.

Hrouda, F., and Jelinek, V., 1990. Resolution of ferrimagnetic and paramagnetic anisotropies in rocks, using combined low-field and high-field measurements. Geophys. J. Int., 103:75-84.

Hrouda, F., and Schulman, K., 1990. Conversion of the magnetic susceptibility tensor into the orientation tensor in some rocks. Phys. Earth Planet. Inter., 63:71-77.

Jackson, M., 1991. Anisotropy of magnetic remanence: a brief review of mineralogical sources, physical origins, and geological applications, and comparison with susceptibility anisotropy. Pure Appl. Geophys., 136:128.
Karson, J.A., Hurst, S.D., and Lonsdale, P.F., 1992. Tectonic rotations of dikes in fast-spread oceanic crust exposed near Hess Deep. Geology. 20:685-688.

Kent, D.V., Honnorez, B.M., Opdyke, N.D., and Fox, P.J., 1978. Magnetic properties of dredged oceanic gabbros and source of marine magnetic anomalies. Geophys. J. R. Astron. Soc., 55:513-537.

Kikawa, E., and Pariso, J.E., 1991. Magnetic properties of gabbros from Hole 735B, Southwest Indian Ridge. In Von Herzen, R.P., Robinson, P.T., et al., Proc. ODP, Sci. Results, 118: College Station, TX (Ocean Drilling Program), 285-307.

Lonsdale, P., 1988. Structural pattern of the Galapagos microplate and evolution of the Galapagos triple junction. J. Geophys. Res., 93:13551-13574.

MacDonald, W.D., and Ellwood, B.B., 1988. Magnetic fabric of peridotite with intersecting petrofabric surfaces, Tinaquillo, Venezuela. Phys. Earth Planet. Inter., 51:301-312.

MacLeod, C.J., and Rothery, D.A., 1992. Ridge axial segmentation in the Oman ophiolite: evidence from along-strike variations in the sheeted dyke complex. In Parson, L.M., Murton, B.J., and Browning, P. (Eds.), Ophiolites and Their Modern Oceanic Analogues. Geol. Soc. Spec. Publ. London, 60:39-64.

McCabe, C., Jackson, M., and Ellwood, B.B., 1985. Magnetic anisotropy in the Trenton Limestone: results of a new technique, anisotropy of anhysteretic susceptibility. Geophys. Res. Lett, 12:333-336.

Nagata, T., 1961. Rock Magnetism: Tokyo (Maruzen).

Nicolas, A., Reuber, I., and Benn, K., 1988. A new magma chamber model based on structural studies in the Oman ophiolite. Tectonophysics, 151:87-105.

Nye, J.F., 1985. Physical Properties of Crystals: New York (Oxford Univ. Press).

Osborn, J.A., 1945. Demagnetizing factors of the general ellipsoid. Phys. Rev., 67:351-357.

Pfleiderer, S., and Halls, H.C., 1990. Magnetic susceptibility anisotropy of rocks saturated with ferrofluid: a new method to study pore fabric? Phys. Earth Planet. Inter., 65:158-164.

Richter, C., and van der Pluijm, B.A., 1994. Separation of paramagnetic and ferrimagnetic susceptibilities using low temperature magnetic susceptibilities and comparison with high field methods. Phys. Earth Planet. Inter., 82:113-123.

Richter, C., van der Pluijm, B.A., and Housen, B.A., 1993. The quantification of crystallographic preferred orientation using magnetic anisotropy. J. Struct. Geol., 15:113-116.

Rochette, P., and Fillion, G., 1988. Identification of multicomponent anisotropies in rocks using various field and temperature values in a cryogenic magnetometer. Phys. Earth Planet. Inter., 51:379-386.

Schmidt, P.W., 1993. Palaeomagnetic cleaning strategies. Phys. Earth Planet. Inter., 76:169-178.

Schultz-Krutisch, T., and Heller, F., 1985. Measurement of magnetic susceptibility in Buntsandstein deposits from Southern Germany. J. Geophys., 57:51-58.

Smith, G.M., and Banerjee, S.K., 1985. Magnetic properties of plutonic rocks from the central North Atlantic Ocean. In Bougault, H., Cande, S.C., et al., Init. Repts. DSDP, 82: Washington (U.S. Govt. Printing Office), $377-383$.

Stephenson, A., 1994. Distribution anisotropy: two simple models for magnetic lineation and foliation. Phys. Earth Planet. Inter., 82:49-54.

Tarling, D.H., and Hrouda, F., 1993. The Magnetic Anisotropy of Rocks: London (Chapman and Hall).

Uyeda, S., Fuller, M.D., Belshé, J.C., and Girdler, R.W., 1963. Anisotropy of magnetic susceptibility of rocks and minerals. J. Geophys. Res., 68:279291.

Wagner, J.-J., Hedley, I.G., Steen, D., Tinkler, C., and Vuagnat, M., 1981. Magnetic anisotropy and fabric of some progressively deformed ophiolitic gabbros. J. Geophys. Res., 86:307-315.

Wolff, J.A., Ellwood, B.B., and Sachs, S.D., 1989. Anisotropy of magnetic susceptibility in welded tuffs: application to a welded-tuff dyke in the Tertiary Trans-Pecos Texas volcanic province, USA. Bull. Volcanol., $51: 299-310$.

Date of initial receipt: 1 August 1994

Date of acceptance: 12 December 1994 Ms 147SR-025 